\title{
Pregnancy outcome at 24-31 weeks' gestation: neonatal survivors
}

\author{
U WARIYAR, S RICHMOND, AND E HEY
}

Regional Perinatal Mortality Survey, Northern Regional Health Authority, Newcastle upon Tyne

SUMMARY All surviving babies of less than 32 weeks' gestation born to mothers resident in the Northern region in 1983 were assessed. No baby was lost to follow up, and 230 long term survivors were assessed when 2 years old, by a single observer. Among 248 neonatal survivors, severe disability was present in 10 of the 37 at 24-27 weeks' gestation (27\%) and in 18 of the 211 at 28-31 weeks' gestation (9\%). On average the surviving babies required 27 days and seven days of intensive care nursing respectively. Babies who were ventilated for more than two weeks and babies who had neonatal fits had a poor prognosis. Because of postneonatal deaths only 20 of the 230 long term survivors of $<32$ weeks' gestation were severely disabled (9\%).

Comparable data were obtained for all babies weighing $1500 \mathrm{~g}$ or less at birth, irrespective of their gestational age. Severe disability was seen in eight of the 49 neonatal survivors (16\%) who had weighed $500-999 \mathrm{~g}$ at birth, and in 17 of the 171 survivors $(10 \%)$ who had weighed $1000-1499 \mathrm{~g}$. The 10 neonatal survivors who had weighed exactly $1500 \mathrm{~g}$ at birth were all well. Only 18 of the 212 long term survivors $(8 \%)$ who had weighed $1500 \mathrm{~g}$ or less at birth were severely disabled.

Because the period of gestation is the only variable known to the obstetrician before delivery, and disability correlates better with gestation than birth weight, future studies should concentrate on relating morbidity, mortality, and the cost of neonatal care to gestation rather than weight at birth.

There have been many publications about the long term prognosis for low birthweight babies. Most have concerned the experience in a single hospital, and reported accumulated data over a number of years. Few have reported the outcome in an unbiased population of all the babies born to mothers living in a defined geographical area in a defined time. Fewer still have provided detailed analyses of all the deaths as well as of disabilities among survivors from such a cohort. No such study has managed to maintain contact with every survivor for two years so that a single clinician could assess the progress of every child consistently.

A study has now been completed in the Northern region of all very low birthweight babies born in 1983. Comparable studies of children born before 1980 had all reported outcome in terms of birth weight, but gestation is the only variable accurately known to the obstetrician before delivery. We therefore report here the developmental progress of every baby born before 32 weeks' gestation in 1983 , as well as the outcome for every neonatal survivor who had weighed $1500 \mathrm{~g}$ or less at birth.

\section{Subjects and methods}

Background information had already been collected (for a parallel study of mortality) for every baby of less than 32 weeks' gestation and every baby weighing $1500 \mathrm{~g}$ or less at birth born in 1983 to a mother normally resident in the Northern region. ${ }^{1}$ Approval for a special follow up survey was obtained from each district's ethics committee. All the children were traced and seen by a single clinician (UW) for assessment on or about their second birthday (21-26 months after birth) in order to make the assessments as consistent as possible. Information from the general practitioners, health visitors, and local paediatricians was available to the doctor before he saw each family, but information about the obstetric and neonatal background was only abstracted from the hospital case notes and entered on a standard form after the assessment had been completed.

Objective measures of disability were obtained so that this study could be compared with similar studies, although precise testing can be difficult in 
children only 2 years old especially if they are shy, restless, or uncooperative. Assessment included a full medical history followed by a complete clinical and neurological examination, including anthropometric measurements and the recording of the blood pressure. A Griffiths's assessment ${ }^{2}{ }^{3}$ was made to obtain a quantitative assessment of developmental progress. Stycar hearing tests were supplemented by free field audiometry in the more cooperative children, and binocular visual acuity was checked with Stycar tests; in half the children this was repeated for each eye separately. The visual fields were checked, and a cover test was done for latent squint. More detailed audiological and ophthalmic information was obtained on all the children with any significant impairment. The clinical findings were always discussed with the parents as soon as the assessment was complete, and arrangements made for further help to be obtained on those occasions where this assessment brought a clinical problem to light for the first time.

\section{Results}

There were 39350 registered births in the Northern region in 1983; 395 of these babies were born before 32 weeks' gestation. There were also 101 babies who were born dead at 24-27 weeks' gestation and whose births were not registered. There were 49 registered stillbirths, and 346 live births before 32 weeks' gestation. Eighty seven of the live born babies died in the first week of life, 11 more died during the next three weeks, and 18 died later in infancy. ${ }^{1}$ There were therefore 230 long term survivors from this cohort two years after delivery (table 1 ).

POSTNEONATAL DEATHS

There were 18 postneonatal deaths (table 2). Eight of these babies had clinical evidence of severe perinatal neurological impairment before death, and this clinical assessment was supported by ultrasound or necropsy evidence of severe parenchymal brain damage, or both, except in the one case where no ultrasound or necropsy examination was undertaken. Six of the 18 babies died after leaving hospital, and only one of these had an impairment that looked as though it was likely to cause disability; all were dead within seven months of delivery.

\section{LONG TERM SURVIVORS}

The detailed developmental progress of the 230 children still alive two years after birth is summarised in fig 1 . Every child with a developmental quotient of less than 70 also had other grounds for being classified as severely disabled. The developmental quotient of the children of more than 26 weeks' gestation who had no motor or sensory disability was normally distributed, but the babies of 24-26 weeks' gestation tended to have a slightly lower developmental quotient-a finding that will call for further scrutiny when the children reach school age.

\section{Severe disability}

Cerebral palsy severe enough to hamper physical activity appropriate to the child's age was judged a severe disability, as was deafness severe enough to warrant a hearing aid (usually equivalent to a hearing loss of $50 \mathrm{~dB}$ or more in the better ear), and blindness or partial sight (usually equivalent to a corrected binocular visual activity of $6 / 60$ or less). A developmental quotient of less than 70 on the Griffiths's assessment scales was also accepted as evidence of severe disability. This threshold was chosen because it is three standard deviations below

Table 1 Mortality and morbidity in babies of 24-31 weeks' gestation

\begin{tabular}{|c|c|c|c|c|c|c|c|}
\hline \multirow{2}{*}{$\begin{array}{l}\text { Gestation } \\
\text { (weeks) }\end{array}$} & \multicolumn{3}{|c|}{ Deaths } & \multicolumn{4}{|c|}{ Survivors at the age of 2 years } \\
\hline & $\begin{array}{l}\text { Born } \\
\text { dead }\end{array}$ & $\begin{array}{l}\text { Neonatal } \\
\text { deaths } \\
(0-27 \text { days })\end{array}$ & $\begin{array}{l}\text { Post- } \\
\text { neonatal } \\
\text { deaths } \dagger\end{array}$ & $\begin{array}{l}\text { Severe } \\
\text { disability }\end{array}$ & $\begin{array}{l}\text { Impairment } \\
\text { without } \\
\text { disability }\end{array}$ & $\begin{array}{l}\text { Minor } \\
\text { impairment }\end{array}$ & Normal \\
\hline 24 & $33^{*}$ & 17 & $1(0)$ & 0 & 0 & 0 & 1 \\
\hline 25 & $29^{*}$ & 15 & 1 (1) & 2 & 0 & 1 & 3 \\
\hline 27 & $14^{*}$ & 15 & 2 (1) & 3 & 0 & 1 & 9 \\
\hline 28 & 10 & 12 & 2 (1) & 2 & 0 & 2 & 22 \\
\hline 29 & 12 & 8 & 2 (1) & 2 & 3 & 4 & 27 \\
\hline 30 & 13 & 13 & $4(2)$ & 3 & 2 & 7 & 47 \\
\hline 31 & 14 & 4 & $5(1)$ & 6 & 2 & 7 & 62 \\
\hline Total & 150 & 98 & $18(8)$ & 20 & 8 & 23 & 179 \\
\hline
\end{tabular}

*Unregistered stillbirths; †number with neurodevelopmental impairment in parentheses. 
Table 2 Postneonatal deaths among babies of $<32$ weeks' gestation or weighing $\leqslant 1500 \mathrm{~g}$ at birth

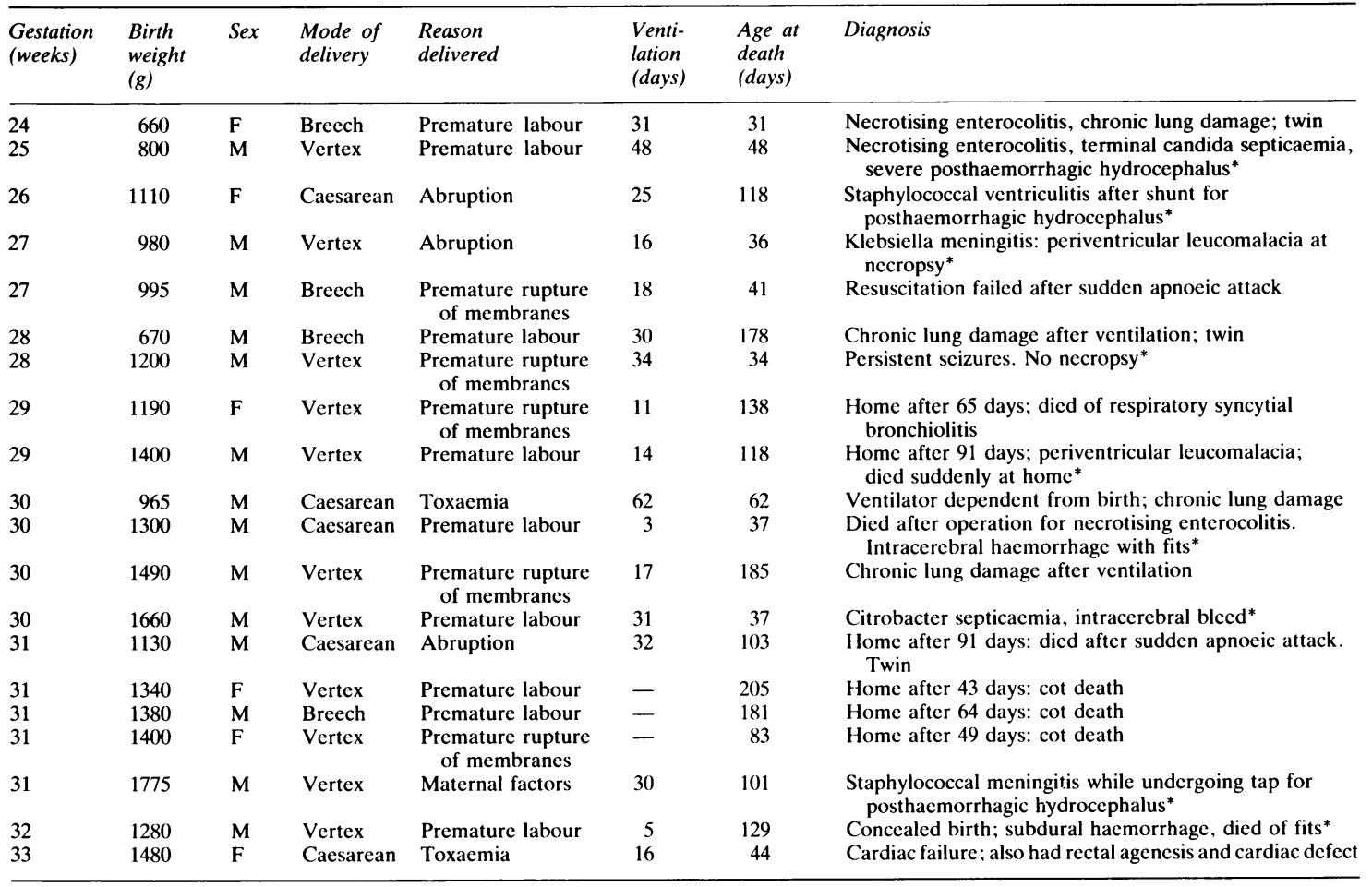

${ }^{*}$ Had severe perinatal neurological impairment.

the mean and identifies continuing serious developmental delay in later childhood with some certainty. We would have classified epilepsy uncontrolled by drugs, chronic malabsorption and growth retardation due to major bowel resection, the loss of a limb, or the presence of a permanent stoma as severe disabilities, but did not find any.

Twenty children were severely disabled, and most of these children had more than one disability (fig 1). Fifteen children had disabling cerebral palsy, and 12 had developmental quotients of less than 70 . Seven children were registered as blind or partially sighted; in four cases this was caused by damage to the central visual pathways, but in three there was severe retinopathy of prematurity. The five children with cerebral palsy as well as visual disability had the lowest developmental quotients in the study. Four children were deaf enough to require hearing aids, but none of the deaf children had had serum bilirubin concentrations of more than $225 \mu \mathrm{mol} / \mathrm{l}$, and only one (a profoundly disabled child of 31 weeks' gestation) had any features of cerebral palsy. Three children had serious epilepsy, but in each case this was well controlled by drugs.
These definitions identify a group of children who had cerebral palsy severe enough to interfere with everyday motor activity, or sensorineural impairment severe enough to be likely to require special educational provision, or both. Nine children had developmental quotients of less than 50. Poor outcomes had been anticipated in some of these children. The only surviving triplet baby (of 25 weeks' gestation) required considerable resuscitation at birth and had early evidence of intracerebral bleeding on ultrasound scan followed by diffuse cystic change (developmental quotient 30). One child had congenital myotonic dystrophy and a developmental quotient of 38 , and another had been ventilated for severe coliform meningitis at the age of 5 days (developmental quotient 22). Four other babies, however, had remarkably uneventful neonatal courses: two were ventilated for less than four days (developmental quotients 11 and 41) and two were not ventilated at all (developmental quotients 8 and 41). Some disability had been anticipated in the remaining two babies because there was ultrasound evidence of intracerebral bleeding (developmental quotients 10 and 18), but 


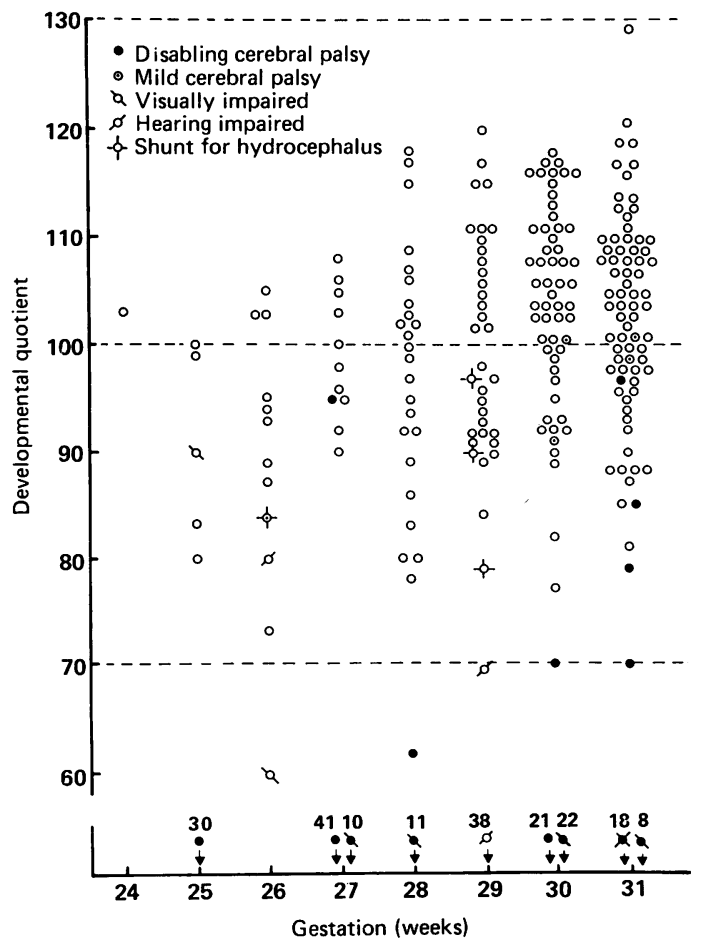

Fig 1 Association between gestation and developmental quotient in all the babies who survived to the age of 2, showing the correlation with other sensorineural impairment. Numbers refer to individual developmental quotients of babies scoring less than 60.

the neonatal courses of these two children did not otherwise differ from those of some of the children who were much less disabled.

\section{Impairment without disability}

Eight children had impairment without disability: five had definite but mild cerebral palsy (usually mild hemiplegia) and four had required ventriculoperitoneal shunts because of posthaemorrhagic hydrocephalus, but were otherwise well without any important neurological disability. Only one had a developmental quotient below 80 (fig 1).

\section{Minor impairment}

A further 23 children had minor impairments. Problems under this heading included squint $(n=17)$, growth retardation after resection of bowel and temporary ileostomy $(n=2)$, severe amniotic bands or talipes requiring operation $(n=2)$, pronounced speech delay with probable conductive hearing loss $(n=1)$, and longstanding ankylosis of both elbows $(n=1)$.

\section{Uncategorised mild developmental delay}

Three children without pronounced motor or sensory impairment had developmental quotients of between 70 and 79 when seen at the age of 2 years (that is, quotients two to three standard deviations below normal). All had deprived backgrounds; in addition, one child had been encased in plaster for late diagnosed congenital dislocation of the hip for more than 12 months, one child's mother had suffered a long severe depression, and the third child came from a family where there had been child abuse. Two of the three children with developmental quotients of 80 had also received little stimulation, and one had spent more than eight months in hospital (fig 1). The effect of the environment on development becomes progressively more important with time, and some or all of these children may need special educational provision in due course. A low assessment quotient at this age, however, may merely mean that the child was shy and uncooperative in unfamiliar surroundings when tested. All the children in this study will be reviewed again at the age of 6 to monitor their growth, validate the assessment of disability made at the age of 2 , and look for signs of poor motor coordination and other important but subtle learning problems.

\section{Babies small for gestational age}

The distribution of birth weight by gestation in this community based study was similar to that recently reported for a hospital based study from Oxford. ${ }^{45}$ Thirteen normally formed babies who were born dead had weights below the fifth centile at delivery, as did three babies who died shortly after birth. Ten babies with weights below the fifth centile survived the neonatal period, though one died later of lung damage after a period of prolonged respiratory support (table 1). The nine long term survivors were well at two years, without any disability or impairment. Others have reported, however, that babies small for gestational age who weighed $1500 \mathrm{~g}$ or less at birth often perform poorly in school. ${ }^{6}$ Similar findings have been reported in babies small for gestational age who were born at full term where there was sonar evidence that fetal growth had started to falter before 27 weeks' gestation. ${ }^{7}$ It will be particularly important, therefore, to reassess these children after they have started school.

\section{Predicting neonatal outcome}

There was only a marginal excess mortality among boys, but 22 of the 28 neonatal survivors with disability were boys, and a preponderance of boys has been noted in other studies. ${ }^{8}$ Overt neonatal fits $^{9}$ were also strongly correlated with severe disability: seven of the 17 neonatal survivors who 
had fits in the first week of life died later in infancy with evidence of severe perinatal neurological impairment, and five long term survivors are also disabled. One other baby survived with a mild left hemiplegia; only four seemed entirely well when 2 years old. Babies ventilated for up to two weeks were only slightly more likely to survive with disability than babies not ventilated at birth $(9 \%$ compared with $5 \%$ ), but babies ventilated for more than two weeks had a high risk of disability (table 3 ).

There seemed to be no correlation between the highest serum concentration of bilirubin recorded in the neonatal period and the risk of disability among long term survivors. Thirty three survivors had had serum bilirubin concentrations of $250 \mu \mathrm{mol} / 1$ or more, but only two of these children were disabled: both had severe spastic quadriplegia and one was also blind but neither was deaf. Two of the three children with disabling retinopathy of prematurity were of less than 27 weeks' gestation and both had received supplemental oxygen for more than 10 weeks (this was also true, however, of 10 children who had no visual problems at follow up); the third child (of 30 weeks' gestation) with retinopathy of prematurity had been ventilated for eight days and given supplemental oxygen for 14 days after developing meningitis when 5 days old.

\section{HOSPITAL CARE}

Figure 2 shows how gestational age influenced the amount of hospital care received by the babies of less than 32 weeks' gestation who died before discharge, and by the survivors. The times spent receiving intensive care (respiratory support) and high dependency care are shown separately because staffing needs make such care particularly expensive. ${ }^{10}$ The babies of less than 32 weeks' gestation accounted for $6 \%$ of all admissions to special care units but $29 \%$ of all nursery cot occupancy in the region during the year of the survey. Three quarters of all the babies ventilated in the region during the year were of less than 32 weeks' gestation, and these babies accounted for $84 \%$ of all non-surgical neonatal ventilator usage ('ventilator nights'). Only 4\% (two of 57 ) of the liveborn babies of 26-27 weeks' gestation and 27\% (23 of 86) of liveborn babies of 28-29 weeks' gestation survived without sustained respiratory support (fig 2), but $58 \%$ (94 of 162) of babies of 30-31 weeks' gestation survived without support, as did $86 \%$ of the babies of 32-33 weeks' gestation.

SURVIVORS OF ANY GESTATIONAL AGE WHO WEIGHED LESS THAN 1500 G AT BIRTH

A separate analysis was undertaken of the outcome

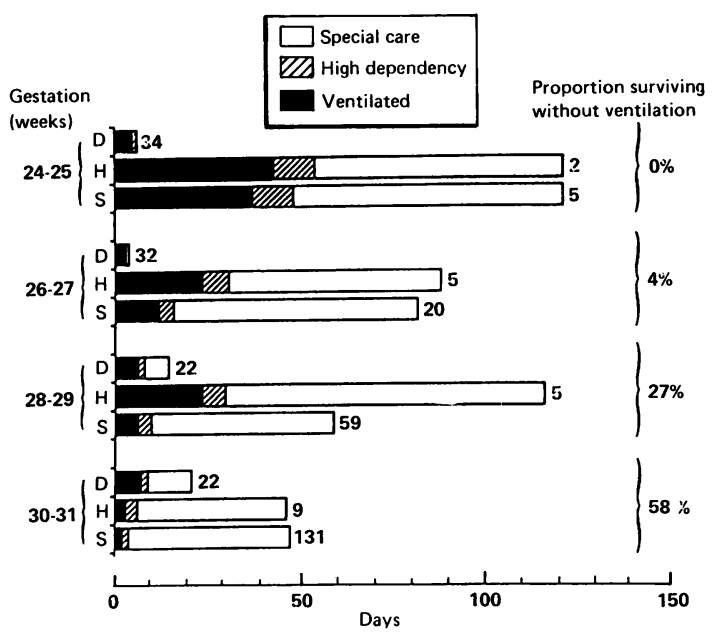

Fig 2 Association between gestational age and average hospital care needs of babies who died before discharge $(D)$ and in the disabled $(H)$ and non-disabled (S) survivors, with care classified in a comparable way with previous costing studies. ${ }^{10}$ The numbers at the end of each histogram bar indicate the number of babies in each group.

Table 3 Correlation between ventilation dependency in days and the risk of severe disability in those who survived for 28 days

\begin{tabular}{|c|c|c|c|c|c|c|}
\hline \multirow[t]{2}{*}{ Outcome } & \multicolumn{6}{|c|}{ No of days ventilated } \\
\hline & 0 & $1-6$ & $7-13$ & $14-20$ & $21-27$ & $\geqslant 28$ \\
\hline \multicolumn{7}{|l|}{$\begin{array}{l}\text { No of survivors at } 28 \text { days } \\
\text { No of later deaths: }\end{array}$} \\
\hline Disabled & 0 & 1 & 0 & 2 & 1 & 4 \\
\hline Not disabled & 3 & 0 & 1 & 2 & 0 & 4 \\
\hline survivors & 6 & 4 & 2 & 1 & 1 & 6 \\
\hline \multicolumn{7}{|l|}{ Percentage of neonatal } \\
\hline survivors disabled & 5 & 9 & 6 & 27 & 30 & 45 \\
\hline
\end{tabular}


for all babies who had weighed $1500 \mathrm{~g}$ or less at birth, whatever their gestational age. There were nine registerable births of less than $500 \mathrm{~g}$, two at 20-23 weeks' gestation, four at 24-31 weeks' gestation, and three at more than 31 weeks' gestation, but none of these babies survived the neonatal period. A further 470 babies weighed between 500 and $1499 \mathrm{~g}$ at birth (table 4). Details of the postneonatal deaths are given in table 2 . Nine babies of 24-31 weeks' gestation and four babies of more than 31 weeks' gestation weighed exactly $1500 \mathrm{~g}$ at birth. One baby was stillborn at 37 weeks' gestation, and two babies died with lethal malformations on the first day of life at 28 and 30 weeks' gestation, respectively. The 10 survivors were all well without disability, when 2 years old.

One hundred and eight babies (including 82 neonatal survivors) of 24-31 weeks' gestation weighed $1500 \mathrm{~g}$ or more at birth, and 96 babies (including 54 survivors) weighed less than $1500 \mathrm{~g}$, although they were more than 31 weeks' gestation at birth.

\section{Discussion}

Every neonatal survivor in this large regional study was accounted for, and every child assessed by the same observer when 2 years old. Some children proved difficult to trace, and others proved difficult to see for assessment though they were traced without difficulty. The amount of disability in these latter groups was much higher than in the $89 \%$ who were contacted without difficulty, ${ }^{11}$ a finding that

Table 4 Outcome at the age of 2 of all babies weighing $500-1499 \mathrm{~g}$ at birth who were born in the Northern region in 1983, irrespective of period of gestation

\begin{tabular}{llc}
\hline Outcome & \multicolumn{2}{l}{ Birth weight } \\
\cline { 2 - 3 } & $500-999 \mathrm{~g}$ & $1000-1499 \mathrm{~g}$ \\
\hline $\begin{array}{l}\text { No of babies born dead } \\
\text { before } 28 \text { weeks' gestation }\end{array}$ & 80 & 3 \\
$\begin{array}{l}\text { No of registered stillbirths } \\
\text { No of neonatal deaths } \\
\quad \text { (0-27 days) }\end{array}$ & 23 & 46 \\
$\begin{array}{l}\text { No of later deaths: } \\
\text { Disabled } \\
\quad \text { Not disabled }\end{array}$ & 61 & 37 \\
$\begin{array}{l}\text { No of disabled long term } \\
\text { survivors }\end{array}$ & 2 & 5 \\
$\begin{array}{l}\text { No of other long term } \\
\text { survivors }\end{array}$ & 4 & 7 \\
\hline $\begin{array}{l}\text { Percentage disability in } \\
\text { long term survivors }\end{array}$ & 6 & 12 \\
\hline
\end{tabular}

points to the importance of tracing and assessing all the survivors in any study of this nature.

POSTNEONATAL DEATH

Eighteen of the 248 babies of less than 32 weeks' gestation who survived the neonatal period died later $(\mathbf{7 \%})$. Six died suddenly, five after discharge from hospital; one neurologically impaired baby probably died of a seizure shortly after discharge but the other five deaths were unexplained, though one baby did have some evidence of bronchopulmonary dysplasia at necropsy. It seems that the risk of sudden infant death in babies born more than eight weeks early may be 10 times as high as in babies born at full term. ${ }^{12}$ Most of the other postneonatal hospital deaths were caused by infection, chronic lung scarring after a period of respiratory support, or necrotising enterocolitis (table 2).

\section{TWIN PREGNANCIES}

Mortality among twins delivered before 32 weeks' gestation was slightly lower than in singletons of comparable gestation in this study ${ }^{1}$ as it was in the National Perinatal Mortality Survey of $1958 .{ }^{13}$ The incidence of disability among survivors was also less than among singletons. This finding is in keeping with other work, suggesting that when twin babies are compared with singletons and matched for gestation a clear excess of cerebral palsy is only seen in comparatively mature twins. ${ }^{14}$ The risk of fetal or early neonatal death in a twin pregnancy of more than 21 weeks' gestation was 10 times as high as it was in singleton pregnancies in this study, largely because of the increased risk of premature labour. Forty six of the 413 twin pregnancies $(11 \%)$ ended before 32 weeks' gestation in 1983, and 42 of 70 $(60 \%)$ of the perinatal mortality associated with twin pregnancy occurred among these babies. Indeed, $53 \%$ of all fetal and early neonatal losses occurred before 29 weeks' gestation, including all but four of the 19 neonatal deaths associated with problems of prematurity. Even if there is any benefit in offering bed rest in twin pregnancies ${ }^{15}$ it would seem to be illogical to delay it until 32 weeks' gestation.

CosT

Much concern has been expressed over the cost of providing medical care for babies as small as this, and studies from North America have suggested that the cost may outweigh the economic benefit for babies weighing below about $1000 \mathrm{~g}$ (if this is calculated in purely monetary terms). Costing exercises in this country have failed to define a particular birth weight below which it is uneconomical to offer sustained intensive care support, but they have 
identified that the average investment put into caring for the babies who did not survive to discharge can be nearly as high as that put into the care of survivors. ${ }^{10}$

No attempt has been made to undertake a full detailed costing of neonatal care in this study, but a realistic estimate can be obtained from a knowledge of cot occupancy and the length of time for which each child required respiratory support or received other high dependency care. On the assumption that the care of the babies requiring respiratory support costs about three times as much as that of babies only requiring special care ${ }^{10}$ it can be seen that the 110 babies who failed to survive to discharge accounted for only about $12 \%$ of the sum spent on caring for all the liveborn babies of 24-31 weeks' gestation before discharge. If babies who failed to survive for at least a day after birth are discounted (as in previous costing studies) the average amount invested in each of the 57 babies who did not survive to discharge is still only a quarter of that invested in the 236 babies who did. Only in babies of 30-31 weeks' gestation did the care invested in the 16 babies who survived more than a day but who failed to survive to discharge exceed the average spent on the 140 babies who did survive to discharge.

Previous costing studies have failed to show any strong correlation between cost and birth weight, ${ }^{10}$ but the data in fig 3 suggest that there is quite a strong correlation between cost and gestational age, and this is further strengthened when individual (rather than average) care costs are analysed. This is of course what would be expected, because very premature babies are usually only robust enough for discharge a week or so before they were due to be born whatever their weight at birth. Thus the 25 surviving babies born at 26-7 weeks' gestation (91 days before term) went home, on average, 84 days after delivery and seven days before they were due to be born (fig 2). Requirements for respiratory

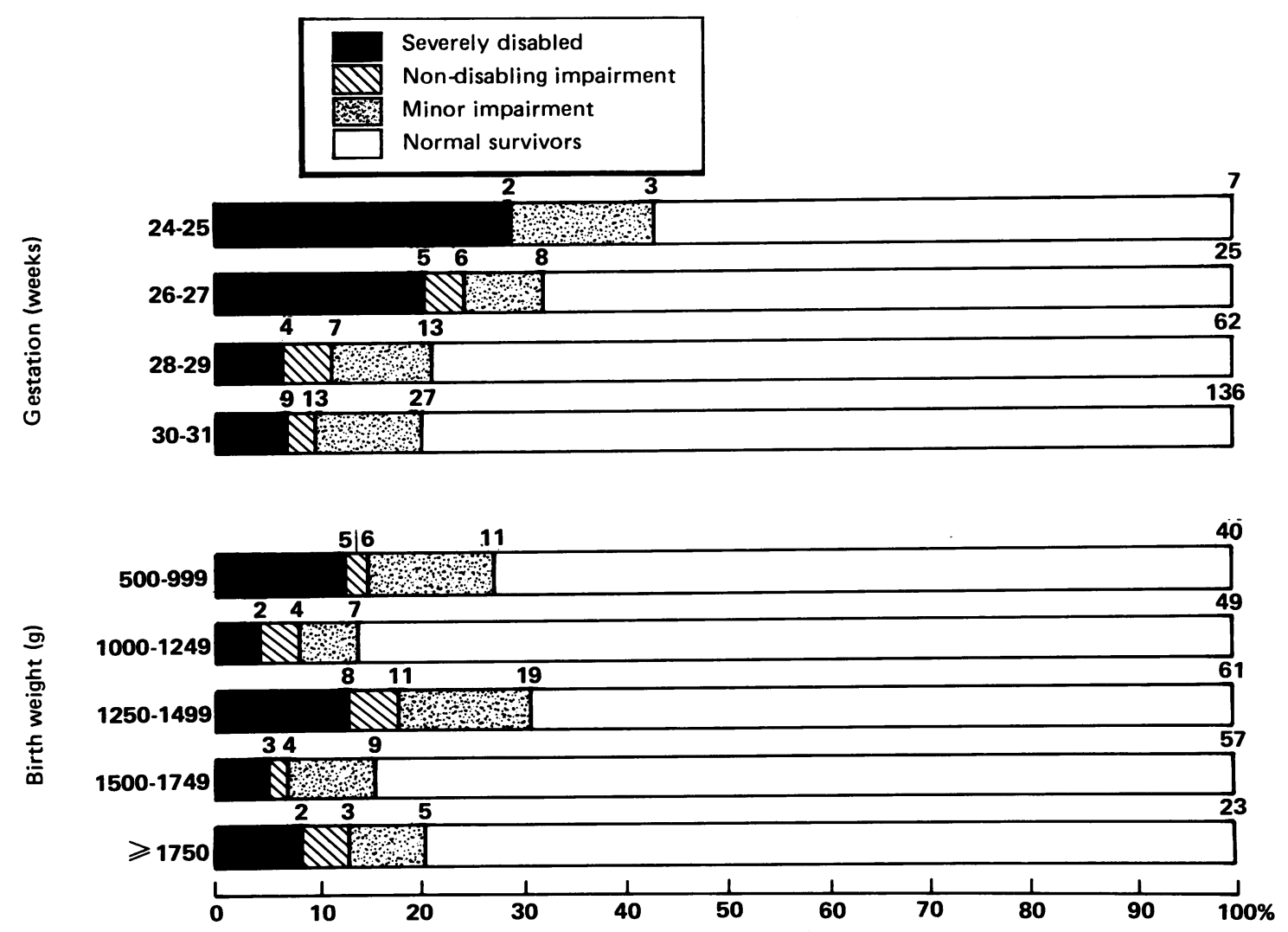

Fig 3 Disability and non-disabling impairment at 2 years in babies of 24-31 weeks' gestation, showing the correlation with gestational age but the lack of correlation with birth weight. 
support and other high dependency care also varied inversely with gestation, with the disabled survivors at each gestation requiring marginally more care and support than the non-disabled survivors (fig 2).

Previous costing exercises have all been undertaken in large referral centres, and have been influenced by the biases caused by selective patient referral, have reflected medical practice in a single centre, and have sometimes only measured cost while in the referral centre rather than total cost to discharge. The broader approach adopted here provides a more accurate picture of the way in which the region's neonatal resources were used by the babies in this study. Such costing exercises, however, have their limitations. Many large unit costs (staff, hospital overheads, and so on) remain the same irrespective of the number of children cared for, or the amount of care invested in each patient. It will always seem cheaper to centralise the care of all babies requiring high dependency care to a few centres in each region to maintain a high cot occupancy, but such a calculation fails to allow for the need for district hospitals to maintain certain minimum neonatal staffing levels whether they undertake the care of babies requiring long term respiratory support or not. The opportunity cost of centralising high dependency care (the scope for redeploying existing staff and facilities in other ways) may be quite small. The case for centralising care depends on the argument that such a policy improves neonatal outcome.

\section{OTHER STUDIES}

Direct comparison with other studies is impossible as all previous population based follow up studies have defined the group of children requiring follow up by birth weight, and used birth weight rather than gestational age to analyse the results obtained. Information was therefore collected about all the babies weighing $500-1500 \mathrm{~g}$ at birth who were born in the region in 1983 (whatever their gestational age). Of the children still alive $92 \%$ had no serious disability at the age of 2 years, a result that is broadly in line with earlier English community based studies from south east London, Mansfield, Wolverhampton, and Liverpool ${ }^{16}$ of babies born between 1963 and 1981, although each of these studies defined disability in a slightly different way. Some classified epilepsy controlled by drugs, asymptomatic posthaemorrhagic hydrocephalus controlled by a ventriculoperitoneal shunt, and minor degrees of cerebral palsy that did not interfere with everyday activity, as evidence of 'disability', but these functional impairments (to use the terminology favoured by $\mathrm{WHO}^{17}$ ) often cause little disability. Nevertheless it seems clear from the available data that increased neonatal survival over the last 20 years has not been associated with any important change in the proportion of long term survivors with serious disabilities.

\section{PROGNOSIS}

The present study highlights the poor prognosis that is associated with early neonatal fits, the increased incidence of disability in babies requiring more than two weeks of respiratory support (which may be partly due to a cross correlation with gestational age, fig 2) and the pronounced excess of male survivors with disabilities.

Outcome also seemed to be influenced by the obstetric factor that precipitated delivery. The chance of long term survival without disability in singleton babies of 24-31 weeks' gestation without malformations who were alive at the onset of labour or delivery was higher when delivery was precipitated by pre-eclampsia $(73 \%)$ or antepartum haemorrhage $(73 \%)$, than it was when spontaneous rupture of membranes before the onset of labour $(60 \%)$, or spontaneous premature labour $(52 \%)$, were the main obstetric factors. As the number of babies in each of these groups is comparatively small, the differences in prognosis may be a chance finding; minor differences in mean gestational age may be a further confounding factor. Nevertheless there is a clear need for further studies of this nature to see if such differences are consistently seen.

Nearly a fifth $(19 \%)$ of the neonatal survivors after spontaneous premature labour were severely disabled, as were $13 \%$ of the neonatal survivors of abruption placentae and other severe antepartum haemorrhages. In contrast, only $3 \%$ of the neonatal survivors delivered because of pre-eclampsia, and $6 \%$ of the survivors whose delivery followed spontaneous rupture of membranes before labour were severely disabled. The mode of delivery had little discernible effect on mortality, or morbidity among survivors, once the obstetric factor precipitating delivery and the gestational age were taken into account. ${ }^{1}$

The main finding of the present study is that though disability in survivors is only poorly correlated with birth weight in babies born more than eight weeks early, it is strongly correlated with gestational age. Severe disability was seen in seven of the 32 long term survivors of 24-27 weeks' gestation $(22 \%)$ and 13 of the 198 survivors of $28-31$ weeks' gestation (7\%) (fig 3). This is in line with the results of other community based studies that have shown that neonatal survival in such babies correlates much more closely with gestation than with birth weight. ${ }^{18}$ The high incidence of disability in long term survivors of less than 28 weeks' gestation 
also confirms the findings from the few hospital based reports in which prognosis was assessed in terms of gestational age. ${ }^{8}$ We believe these findings strengthen the case for using gestational age rather than birth weight as the yardstick by which to measure outcome in all future studies of perinatal mortality and morbidity, even though analyses by birth weight are, for the moment, the only way of comparing recently collected data with studies on babies born before 1980 .

Obstetricians urgently need better and more detailed information on long term prognosis if they are to make informed decisions about the management of mothers who require delivery, or who threaten to deliver spontaneously, more than eight weeks before full term. Parents themselves also need such information if they are to be concerned in and consulted about management when problems of this nature arise. At this stage the obstetrician will know which is the primary factor complicating the pregnancy, and will have a good idea of the baby's gestational age, but will only have an imperfect assessment of the baby's weight.

These considerations point to the logic of reporting both short and long term outcome in terms of gestational age rather than birth weight. Resistance to such an idea has usually been based on a feeling that, though birth weight had been documented with some precision, information on gestation is necessarily imprecise. Though this is undoubtedly true, the need for precision can be exaggerated because children are usually subdivided into $100 \mathrm{~g}$ (or $250 \mathrm{~g}$ ) birth weight groups for analytical and prognostic purposes. Furthermore, the advent of ultrasound scanning and of other techniques for dating pregnancies $^{19}$ have now increased the accuracy with which gestational age can be determined in early pregnancy. The case note review undertaken during the present study showed that serious errors often crept into the calculation and documentation of gestational age, but it also showed that the various primary criteria used to assess gestational age seldom gave estimates that differed by more than 10 days.

We conclude that although the routine documentation of gestational age at delivery is often unreliable at present this is not because precision is impossible,but because the need for precision is not recognised. As data continue to accumulate showing that gestational age rather than weight is the most powerful predictor of mortality and morbidity at birth in preterm babies, the importance of documenting gestation properly and the value of analysing long term outcome by gestational age, should become more generally recognised.
This study would not have been possible without the help that the region's paediatricians gave by retrospectively tracing the surviving children. We also owe a deep debt to the families of the children in the study. We are particularly grateful to Mrs B Gibson for her skill and commitment in gaining the cooperation and trust of the families, and in tracing those who had moved; it was her persistence and dedication that finally ensured that no child was lost to follow up. Dr Wariyar was a research registrar funded by the Regional Health Authority at the time of the study.

\section{References}

1 Wariyar U, Richmond S, Hey E. Pregnancy outcome at 24-31 weeks' gestation: mortality. Arch Dis Child 1989;64:670-7.

${ }^{2}$ Griffiths R. The abilities of young children. London: Child Development Research Centre, 1970.

${ }^{3}$ Griffiths R. The abilities of babies. Amersham: Association for Research in Infant and Child Development, 1954.

4 Yudkin PL, Aboulfa M, Eyre JA, Redman CWG, Wilkinson AR. Influence of elective preterm delivery on birthweight and head circumference standards. Arch Dis Child 1987;62:24-9.

5 Yudkin PL, Aboulfa M, Eyre JA, Redman CWG, Wilkinson AR. New birthweight and head circumference centiles for gestational ages 24-42 weeks. Early Hum Dev 1987;15:45-52.

6 Francis-Williams J, Davies PA. Very low birthweight and later intelligence. Dev Med Child Neurol 1974;16:709-28.

7 Parkinson CE, Wallis S, Harvey D. School achievement and behaviour of children who were small-for-dates at birth. Dev Med Child Neurol 1981;23:41-50.

8 Yu VYH, Loke HL, Bajuk B, Szymonowicz W, Orgill AA, Ashbury J. Prognosis for infants born at 23 to 28 weeks gestation. Br Med J 1986;293:1200-3.

9 Watkins A, Szymonowicz W, Jin X, Yu VVY. Significance of seizures in very low-birthweight babies. Dev Med Child Neurol 1988;30:162-9.

10 Sandhu B, Stevenson RC, Cooke RWI, Pharoah POD. Cost of neonatal intensive care for very-low-birthweight infants. Lancet 1986;i:600-3.

"Wariyar U, Richmond S. Morbidity and preterm delivery: importance of $100 \%$ follow-up. Lancet 1989 ;i:387-8.

12 Yu VYH, Watkins A, Bajuk B. Neonatal and postneonatal mortality in very low birthweight infants. Arch Dis Child 1984;59:987-9.

13 Butler NR, Alberman ED. Perinatal problems. Edinburgh: Churchill Livingstone, 1969:131.

14 Alberman ED. Cerebral palsy in twins. Guy's Hospital Report 1964;113:285-95.

is Saunders MC, Dick JS, Brown IMcL, McPherson K, Chalmers I. The effect of hospital admission for bedrest on the duration of twin pregnancy: a randomised trial. Lancet 1985;ii:793-5.

16 Powell TG, Pharoah POD, Cooke RWI. Survival and morbidity in a geographical defined population of low birthweight infants. Lancet 1986;i:539-43.

17 World Health Organisation. International classification of impairments, disabilities and handicaps. Geneva: World Health Organisation, 1980.

18 Verloove-Vanhorick SP, Verwey RA, Brand R, Bennebroek Gravenhorst J, Keirse MJNC, Ruyns JH. Neonatal mortality risk in relation to gestational age and birthweight. Lancet 1986;i:55-7.

19 Whittaker PG, Lind T, Lawson JY. A prospective study to compare serum human placental lactogen and menstrual dates for determining gestational age. Am J Obstet Gynecol 1987;156: 178-82.

Correspondence to $\mathrm{Dr}$ U Wariyar, Princess Mary Maternity Hospital, Great North Road, Newcastle upon Tyne NE2 3BD.

Accepted 18 November 1988 